\title{
O TRABALHO COMO OBJETO MÉDICO-LEGAL EM SÃO PAULO DOS ANOS 30
}

\author{
Luis Ferla \\ Doutor em História pela Universidade de São Paulo e professor de pós-graduação na \\ Fundação Armando Álvares Penteado, em São Paulo.1
}

\begin{abstract}
RESUMEN
A medicina legal praticada em São Paulo dos anos 30 estava impregnada de teses biodeterministas. Buscando harmonizar corpo e trabalho, os profissionais da área objetivavam racionalizar tanto o «tratamento» de delinqüentes, quanto a produtividade e disciplina fabris. Por isso, um dos eixos centrais de seu discurso era o tema do trabalho. O presente artigo analisa o conteúdo deste discurso.
\end{abstract}

PALABRAS CLAVE: Medicina legal, criminología, trabajo, antropología criminal, Brasil.

\section{SUMMARY}

The legal medicine practised in São Paulo in the years 1930 was deeply influenced by biodeterminism theses. In an attempt to harmonise body and work, professionals in the area aimed at rationalising the «therapeutic treatment» of delinquents, as well as the factory discipline and productivity. Thus one of the main points in their discourse was the theme related to work. The present article analyses the content of such a discourse.

KEY WORDS: Legal medicine, criminology, work, criminal anthropology, Brazil.

\section{INTRODUÇÃO}

A medicina legal do período entre-guerras pensou e concebeu o trabalho enquanto objeto científico. De seu ambiente intelectual saíram propostas de intervenção no mundo do trabalho a partir de critérios médicos, marcadamente influenciados pela biotipologia. Este artigo pretende abordar esse discurso

1 A pesquisa que deu origem ao presente texto só foi possível graças à bolsa concedida pela CAPES, órgão do Ministério da Educação do Brasil, para viabilização de estágio no Departamento de Historia de la Ciencia del Consejo Superior de Investigaciones Científicas (CSIC), de Madri, realizado de setembro de 2003 a março de 2004. 
e algumas de suas implicações práticas, priorizando os espaços repressivos de confinamento, como as penitenciárias e casas de correção, por um lado, e o mercado de trabalho industrial, por outro. Como será a intenção demonstrar, em todos esses ambientes a presença cotidiana e dirigente da medicina legal era sistematicamente reivindicada e valorizada.

O presente estudo é parte de um mais amplo que corresponde à pesquisa de doutoramento do autor e que trata da influência da Escola Positiva de direito penal na medicina legal praticada em São Paulo entre 1920 e 1945. Esta escola, herdeira do pensamento de Cesar Lombroso e com grande penetração no Brasil, se caracterizava por um discurso médico-científico que patologizava o ato anti-social ${ }^{2}$. Isso implicava numa tranferência de ênfase do objeto jurídico do crime para o objeto científico do criminoso. O crime em si deveria ser considerado apenas enquanto evento revelador de aspectos da personalidade anormal do criminoso. Em última análise, o delinqüente seria um doente; o crime, um sintoma; a pena ideal, um tratamento.

A medicina legal, no período estudado, se ocupava dessas questões. A impregnação de teses do determinismo biológico levava a medicina legal a uma atitude reivindicatica em busca de prerrogativas profissionais e sociais que pudessem colaborar na «defesa da sociedade», principalmente por meio da generalização do «direito de examinar». O exame médico se constituía, então, em instrumento para identificar anomalias e desvios que pudessem comprometer o equilíbrio social ${ }^{3}$. Os médicos legistas e seus aliados institucionais,

2 Deve-se reconhecer, no entanto, que a Escola Positiva sofreu grandes transformações desde a época de Lombroso até o período aqui abordado, dentre elas o abandono do reducionismo simplista que centrava o julgamento do caráter a partir de elementos puramente morfológicos, e o fortalecimento de perspectivas mais psicologizadas. No entanto, o que sim permite identificar uma linha de continuidade é a permanência da patologização do ato anti-social, ainda que orientada por conhecimentos médicos mais sutis e sofisticados. Para uma abordagem de Lombroso e a Escola Positiva, ver Peset, J. L. e Peset, M. (1975), Lombroso y la Escuela Positivista italiana, Madrid, CSIC. Para um exercício comparativo sobre a mesma temática na Argentina, consultar HuERTAS, R. (1991), El delincuente y su patologia - medicina, crimen y sociedad en el positivismo argentino, Madrid, CSIC; ou, para conhecer a história da influência dessas idéias no ambiente jurídico brasileiro, ver Alvarez, M. (1996), Bacharéis, criminologistas e juristas - saber jurídico e nova escola penal no Brasil (1889-1930), tese de doutoramento, São Paulo, FFLCH.

3 Em outro texto, procuro desenvolver uma análise da arquitetura interna e do lugar ocupado pelo exame médico-legal na concretização das idéias biodeterministas em criminologia (FerLA, L. A. C. (2003), O exame médico legal e o biodeterminismo em São Paulo (19201945). In: Anais eletrônicos do XXII Simpósio Nacional de História, João Pessoa, ANPUH, formato compact disc). 
com essa perspectiva, estariam sistematicamente reivindicando o reconhecimento da importância dos exames e laudos médicos, aplicáveis nos mais diversos ambientes sociais, como a escola, a prisão, a fábrica, ou a fila da busca de emprego. A visão biologizada do comportamento humano fazia com que a intervenção da medicina se apresentasse como indispensável sempre que as atitudes de um indivíduo estivessem sob alguma forma de apreciação. Nesse sentido, o universo desejado pela Escola Positiva não levava em conta os muros das delegacias e penitenciárias. Parte dele se concretizava no mundo do trabalho, considerado nos dois lados destes muros. O objetivo deste texto é discutir essa parte, abordando a concepção de trabalho como terapêutica penal, sua racionalização médica na fábrica e a resposta científica à desorganização representada pelo acidente e pela doença profissional.

\section{O TRABALHO COMO TERAPÊUTICA PENAL}

A medicina legal concebia o trabalho como seu objeto de reflexão em sentido bastante amplo. Por um lado, como será discutido mais adiante, tratava-se tanto de colaborar na racionalização científica da produção, como de evitar acidentes e doenças profissionais. Por outro, o trabalho era considerado como a mais privilegiada estratégia de regeneração de indivíduos «descaminhados». Na perspectiva dos positivistas ${ }^{4}$, se o delinqüente era um enfermo, a terapêutica mais indicada era o trabalho. O trabalho como terapia no tratamento do delinqüente partia da concepçäo central da Escola Positiva, que via neste um enfermo com predisposições psico-biológicas ao ato anti-social. Estas predisposiçöes podiam ser potencializadas pelo meio social, se este tampouco fosse saudável, ou, pelo contrário, restringidas e anuladas, em caso de um meio higiênico e moralizador. Assim, as análises das relaçöes do homem com o seu meio, particularmente do indivíduo desviante, estavam impregnadas de metáforas ligadas à microbiologia pasteuriana. $\mathrm{O}$ criminoso «potencial» seria um micróbio. Se o ambiente fosse nocivo, assim considerado sob uma perspectiva bastante ampla, que incluía higiene, moral, alcoolismo, educação, e tudo o que importava ao discurso normalizador, o micróbio podia acabar por causar malefícios ${ }^{5}$. Assim, apesar da visão forte-

\footnotetext{
4 Nesse texto, o termo «positivista» será utilizado em alusão a adeptos da Escola Positiva de direito penal.

5 Para uma discussão da metáfora microbiológica em criminologia nos tempos gloriosos do degeneracionismo francês de fins do século XIX, ver HARRIS, R. (1993)[1989], Assassinato e loucura. Medicina, leis e sociedade no fin de siècle, Rio de Janeiro, Rocco.
} 
mente biologizada do comportamento humano, era o entorno social prejudicado que deveria e poderia sofrer intervenção, não diretamente o corpo humano. Daí a necessidade da seqüestração do desviante em casos de ambientes ou indivíduos demasiadamente degradados. Um meio social de disciplinarização e moralização, estruturado em torno ao trabalho, poderia ser capaz de constranger as tendências e predisposições anti-sociais ${ }^{6}$.

Por outro lado, a regeneração de que se trata aqui é essencialmente a regeneração da utilidade social do condenado. Utilidade compreendida não apenas a partir de seu aspecto diretamente econômico, mas também por uma dimensão normalizadora e moralizadora, ao permitir que a disciplina implicada no ato de trabalhar pudesse se transmutar em disciplina social e constrangimento da atitude delinqüente. Foucault, quando analisa a penitenciária, aborda a utilidade do trabalho e os mecanismos pelos quais opera no corpo e na consciência do condenado:

«Não é como atividade de produção que ele é intrinsecamente útil, mas pelos efeitos que toma na mecânica humana. É um princípio de ordem e regularidade; pelas exigência que lhe são próprias, veicula, de maneira insensível, as formas de um poder rigoroso; sujeita os corpos a movimentos regulares, exclui a agitação e a distração, impõe uma hierarquia e uma vigilância que serão ainda mais bem aceitas, e penetrarão ainda mais profundamente no comportamento dos condenados (...).» ${ }^{7}$

Esta perspectiva não era exclusiva dos médicos preocupados com o tema. No ambiente médico-legal, a priorização do trabalho enquanto terapêutica penitenciária não costumava contrapor médicos e juristas. Por exemplo, assim se manifestava Basileu Garcia, um dos principais juristas da época e então professor catedrático de Direito Penal da Faculdade de Direito da Universidade de São Paulo:

«O trabalho é uma imperiosa necessidade no cárcere. (...) Para ser possível a regeneração do delinqüente é preciso que ele se entregue a uma ocupação útil, que lhe constitua um meio de cura, impedindo-o de voltar aos seus antigos maus pensamentos, às suas diabólicas maquinações, e que lhe favoreça a obtenção de meios para viver honestamente depois que saia do cárcere. Na ociosidade, que é a mãe de

6 Essa concepção se pretendia crítica àquela do primeiro lombrosionismo, que negligenciava quase absolutamente as influências do meio. Deve-se lembrar, no entanto, que o próprio Lombroso, em seu últimos anos de vida, reconhecia a necessidade de matizar o exclusivismo da etiologia biológica do crime.

7 Foucault, M. (1999) [1975], Vigiar e Punir - História da Violência nas Prisões, 20. ed., Petrópolis, Vozes, p. 203. 
todos os vícios, está muita vez a razão dos crimes. (...) O trabalho penal, visando a regeração do delinqüente, deve também colimar a sua ressocialização, no sentido de que lhe torne possível mais tarde uma vida proveitosa à sociedade, como elemento útil integrado à comunhão social.» ${ }^{\mathbf{8}}$ (Grifos meus).

Mas não se tratava apenas de fazer o condenado trabalhar. O trabalho dentro das prisões também deveria ser racionalizado cientificamente, de forma a otimizar as possibilidades de regeneração. Para isso, havia que se reconhecer o papel da medicina biotipológica. Dentre suas diversas funções, estaria a de possibilitar uma melhor individualização da pena, reivindicação central da Escola Positiva, por meio da orientação profissional biotipologicamente realizada. «Não há doenças, mas doentes. Não há crimes, e sim criminosos», era a divisa repetida à exaustão pelos positivistas da época. Por isso, a necessidade de conhecer a fundo o indivíduo delinqüente, já que esse conhecimento permitiria a prescrição do tratamento mais adequado. Daí também as recorrentes críticas que os criminologistas e médico-legistas faziam às limitações das instituições carcerárias em fornecer ao preso uma variedade de ofícios profissionais que permitisse satisfazer suas «aptidões, predisposições e necessidades terapêuticas personalíssimas». A criação, em 1941, da Colônia Penal Agrícola de Taubaté obedeceu a essas pressões. Além disso, em 1939, a Penitenciária de São Paulo criava o seu Laboratório de Biotipologia Criminal, buscando aprimorar sua estrutura científica para contemplar tais objetivos ${ }^{9}$.

Ao se contrapor o programa e o discurso, o balanço das conquistas da criminologia positivista nesse campo é necessariamente parcial. Se por um lado lograram a criação de instituições voltadas a seus objetivos, como as referidas acima, com o reconhecimento de prerrogativas que estas instituições implicavam, por outro as lamentações em torno da insuficiência destas mesmas instituições e prerrogativas impregnavam as explicações do fracasso do regime penitenciário, cada vez mais incontornavelmente admitido à medida que passavam os anos 30. No entanto, do que os positivistas apresentavam de ativo nesse balanço, grande parte se devia ao ambiente ideológico da época, não apenas com relação às necessidades de controle e defesa social, e ao reconhecimento do papel da ciência nisso, mas ao discurso de «valorização» do

8 GARCIA, B. (1942), «Regimes adequados ao cumprimento das penas de reclusão e detenção - estabelecimentos de prisão provisória», Arquivos da Polícia Civil de São Paulo, 4 , 617-624, p. 622.

9 Para uma reflexão sobre essas questões contemporânea aos acontecimentos, ver ÁsSALY, A. (1945), «Sugestões para a reforma do regulamento da penitenciária de São Paulo», Arquivos da Polícia Civil de São Paulo, 10, 31-50. 
trabalho que se procurava disseminar, principalmente desde os próprios escritórios do aparelho estatal.

\section{A «VALORIZAÇÃO» DO TRABALHO E O NÃO-TRABALHO COMO PERIGO}

Tanto olhando para dentro dos muros das prisões quanto para o interior da fábrica, a medicina legal compartilhava e conferia cientificidade à valorização do trabalho que impregnava a ideologia e a política do Governo Vargas dos anos $30^{10}$. A retórica varguista de valorização do trabalho pretendia fornecer suporte ideológico ao reordenamento do mercado do trabalho que se empreendia então sob a direção do Estado. Esse reordenamento, por sua vez, atendia às demandas por modernização capitalista e disciplinarização da mãode-obra, na esteira da crise de 29 e das convulsões sociais dos anos 20 . Ângela de Castro Gomes chama a atenção para o fato de que a força e onipresença da retórica da valorização do trabalho eram tanto maiores e necessárias quanto mais se tivesse em conta que a sociedade brasileira foi escravocrata por 400 anos e foi a última a deixar de sê-lo ${ }^{11}$. O trabalho que sujava a mão também sujava a alma, e era justamente este estigma que se buscava definitivamente superar.

Por outro lado, o estigma que deveria desaparecer no trabalhador deveria ser reforçado no desocupado. Se o trabalho era terapia e regeneração, inversa mas coerentemente o não-trabalho era considerado causa paradigmática do ato anti-social. Por isso, junto com o «menor», o chamado «vadio» ${ }^{12}$ aparecia como o pré-delinqüente por excelência. Como afirmava Basileu Garcia um pouco mais acima, «na ociosidade, que é mãe de todos os vícios, está muita vez a razão dos crimes». $\mathrm{O}$ «vadio», intrinsicamente perigoso, também deve-

10 Getúlio Vargas governou o Brasil por dois períodos: de 1930 a 1945 e de 1951 a 1954 , quando se suicida por conta de uma grave crise política. $\mathrm{O}$ seu governo ditatorial corresponde ao primeiro período, já que o segundo fazia parte de um interregno democrático no Brasil (de 1945 a 1964). Foi a chamada «Revolução de 30» que o alçou ao poder, em nome de uma «modernização autoritária» que postulava superar o domínio da oligarquia cafeeira paulista. Em 1937, Vargas patrocina um «auto-golpe», inaugurando a fase mais dura do regime, conhecida como «Estado Novo», por fim colapsado pela onda redemocratizadora de 1945.

11 Gomes, A. de C. (1999), Ideologia e trabalho no Estado Novo. In: PANDOLFI (org.). Repensando o Estado Novo, Rio de Janeiro, Editora FGV, p. 55.

12 Mantém-se aqui, para «menor» e «vadio», os termos utilizados nos documentos estudados, mas a presença das aspas indica a consciência do aspecto problemático dessa terminologia, dado o sentido estigmatizante que acabou por adquirir. 
ria ser de alguma forma seqüestrado e submetido à redisciplinarizaçäo do trabalho. Com essa perspectiva, Flamínio Fávero, com a autoridade de professor de Medidina Legal da Universidade de São Paulo, presidente da Sociedade de Medicina Legal e Criminologia de São Paulo ${ }^{13}$ e Diretor Geral de Presídios deste estado, defendia que o Poder Público deveria garantir que o cotidiano de trabalho do egresso das prisões não sofresse solução de continuidade ao recomeçar este a vida em liberdade, alertando também para os perigos da ociosidade:

«Básico, é o trabalho. O egresso, que traz o aprendizado e o treino intensivo de um ofício, precisa trabalhar. E logo. (...) O trabalho é a arma de ação eficaz para todas as vitórias, para a saúde e para a vida. (...) A inatividade enferruja as máquinas e desmantela a economia de um povo. É pelo trabalho que o ser físico se integra em todas as suas funções, atingindo a plenitude de sua finalidade, no desenvolvimento metódico e eficiente dos seus órgãos, sistemas e aparelhos e, também, se mantém em boa saúde. (...) A ociosidade é chave para a prisão, caminho certo para as doenças e enxada que cava a sepultura do indivíduo e, também, de um povo» ${ }^{14}$.

Alfredo Issa Ássaly, burocrata de carreira no mundo jurídico-policial, Secretário da Segurança Pública de São Paulo de 1943 a 1945, era um estudioso dedicado do tema do trabalho e também se mostrava particularmente preocupado com a «vagabundagem» e a mendicidade. Pare ele, as instituições centrais nesse caso seriam a polícia e as chamadas casas de correção ${ }^{15}$, concebendo um papel prioritário para a medicina. À polícia caberia o «recrutamento» dos desocupados e o estudo médico-científico de cada um, com o objetivo de classificá-los e encaminhá-los ao «tratamento» mais adequado. Ássaly considerava que

«(...) a investigação da etiologia da vagabundagem e da mendicância deve ter início desde a prisão policial para 'averiguações', estudando-se a individualidade dos que são conduzidos à presença das autoridades policiais como vadios, mendigos, ébrios habituais ou como de tal suspeitos. É a polícia quem recebe - de iní-

13 A Sociedade de Medicina Legal e Criminologia de São Paulo foi fundada em 1921, tornando-se desde seu início um centro importante da criminologia positivista. Nesse artigo, aparecerá nomeada também como «Sociedade de Medicina Legal», ou simplesmente «Sociedade».

14 Flávero, F. (1944), «Higiene mental e egressos dos presídios», Arquivos da Polícia Civil de São Paulo, 8, 335-338, p. 336 a 337.

15 O estado de São Paulo possuía, desde 1902, mas fucionando desde então com muitas descontinuidades, uma «colônia correcional» na Ilha Anchieta, direcionada para abrigar mendigos e «vagabundos». Em 16 de setembro de 1943 é inaugurado o Recolhimento da Penha, na cidade de São Paulo, com a mesma finalidade. 
cio - toda a escumalha social, os perturbadores da ordem e os indivíduos perigosos. O estudo desses mal-viventes deve ser feito por um serviço especializado, tendo-se em vista a constituição sômato-psíquica dos mesmos, os seus antecedentes policiais, judiciários, econômicos e sociais, de maneira a ser possível classificá-los à luz de um critério antropo-social, verificando-se se são doentes, anômalos, inválidos, desempregados, ociosos válidos, ocasionais ou professionais, a fim de ser determinada medida hospitalar, de assistência social ou a instauração do competente processo de contravenção, para efeito de recolhimento em estabelecimento adequado.» ${ }^{16}$ (Grifo do autor).

Na visão de Ássaly, esse estudo do indivíduo permitiria decidir não apenas o seu destino institucional, mas também a «natureza de trabalho que concorrerá para sua reabilitação» ${ }^{17}$.

De uma forma geral, era dessa maneira que a medicina legal positivista enxergava o trabalho nos espaços repressivos de regeneração de indivíduos desviados, sejam presidiários ou «vagabundos». No entanto, mesmo na fábrica, espaço teoricamente mais normalizado e lugar ideal de destino dos indivíduos disciplinados ou re-disciplinados, a medicina se fazia necessária enquanto saber especializado capaz de identificar desvios e tratá-los devidamente ${ }^{18}$. A fábrica também era lugar de desajustes, e o acidente de trabalho era dos mais freqüentes e preocupantes.

\section{O INTERESSE MÉDICO-LEGAL PELO ACIDENTE DE TRABALHO}

Dentro da fábrica, a medicina legal se propunha a auxiliar na racionalização do trabalho e na melhor adaptação do operário ao espaço e à disciplina fabris, como se discutirá mais adiante. $\mathrm{O}$ acidente do trabalho aparecia então

16 Ássaly, A. I (1944), «Trabalho a mendigos e vagabundos». Arquivos da Polícia Civil de São Paulo, 7, 5-13, p. 8.

17 Ibidem, p. 9.

18 Evidentemente, a fábrica desde há muito havia sido espaço de moralização da classe operária, antes mesmo dos esforços científicos de racionalização do trabalho. Tradicionalmente, procurava-se estabelecer «(...) uma vinculação entre a obediência às regras de boa moral e a disciplina da fábrica.» (FAusto, B. (1984), Crime e cotidiano - a criminalidade em São Paulo (1880-1924), São Paulo, Brasiliense, p. 220). No entanto, há que se registrar que Roberto Machado, ao tratar do século XIX, parece não identificar o mesmo fenômeno: «A fábrica não é ainda instituição criada para produzir, através de mecanismos disciplinares, o bom trabalhador». (MACHADO, R. et al. (1978), Danação da Norma - Medicina social e constituição da psiquiatria no Brasil, Rio de Janeiro, Graal, p. 349). 
como o elemento perturbador dessa ordem racionalizada, e por isso receberia atenção dedicada da medicina legal, que era àquela época também medicina do trabalho. O tema da infortunística ocupava lugar central entre as preocupações da medicina legal ${ }^{19}$. Assim era não apenas porque a medicina do trabalho ainda não existia enquanto especialidade autônoma ${ }^{20}$, permanecendo o tema objeto legítimo da medicina legal, mas principalmente porque era considerado em si mesmo um tema de primeira relevância. A Sociedade de Medicina Legal, por exemplo, freqüentemente trazia o assunto para a discussão em suas sessões ${ }^{21}$. De muitas delas saíram propostas de reformas legislativas sobre o tema. Assim foi quando da elaboração e promulgação das leis de acidentes de trabalho de 1934 e 1944, momentos nos quais o papel da Sociedade foi de grande protagonismo ${ }^{22}$. Flamínio Fávero, ao fazer um balanço de 15 anos da entidade, em 1936, nomeava as questões que foram privilegiadas no período, e os acidentes de trabalho aí apareciam:

«Não desmerecendo os demais [capítulos da medicina legal e da criminologia], permito-me salientar o interesse de que foram cercados: a necessidade da reforma do Código Penal, o valor do testemunho, a questão do médico e a responsabilidade

19 Mariza Corrêa localiza o início da relação da medicina legal positivista com o tema dos acidentes de trabalho na década de 20 (CORRÊA, M. (1998), As Ilusões da Liberdade - A Escola Nina Rodrigues e a Antropologia no Brasil, Bragança Paulista, EdUSF, p. 34).

20 Está, na verdade, começando a se constituir autonomamente, a partir de prescrições da lei de acidentes de trabalho de 1934, mas ainda de forma incipiente e pouco institucionalizada. Almeida Júnior, por exemplo, já em 1941, apontava a inexistência de qualquer curso da especialidade no Brasil (AlmeIda JúNIOR, A. (1941), « Medicina e infortunística», Arq. Soc. Med. Leg. Crim. S. Paulo, 12, suplemento, 299-359, p. 308).

21 A Sociedade possuía no seu organograma, inclusive, uma seção de infortunística.

22 Para conhecer reflexões referentes à lei de 1934 (decreto 24637 de 10 de julho de 1934), ver: FÁvero, F. (1934), «A nova lei de accidentes do trabalho», Arch. Soc. Med. Leg. Crim. S. Paulo, 5, 55-60. Já com relação à lei de 1944 (decreto 7036, de 10 de novembro de 1944), ver as sessões de 30 de abril, de 14 de maio e 31 de maio de 1943 da Sociedade (Arq. Soc. Med. Leg. Crim. S. Paulo, 14, (1-3), 1943, 33-39 e 59-62), ou, ainda, Leme, J. de M. (1944), «Projeto da nova lei de acidentes do trabalho», Arq. Soc. Med. Leg. Crim. S. Paulo, 15, (1-3), 67-75, que tratam de discussões prévias à promulgação; ou, FÁvERO, F.(1945), «O conceito de acidente de trabalho na nova lei», Arq. Soc. Med. Leg. Crim. S. Paulo, 16, (1-3), 5-8, e LEME, J. de M. (1945), «Alguns aspectos médicos da nova lei de acidentes do trabalho», Arq. Soc. Med. Leg. Crim. S. Paulo, 16, (1-3), 42-51, como exemplos já de uma interpretação da referida lei. Quando da promulgação da lei de 1919 (decreto 3724, de 15 de janeiro), a Sociedade todavia ainda não existia. 
dos criminosos, a perícia das armas de fogo e as questões sempre momentosas dos acidentes de trabalho, em seu duplo aspecto curativo e profilático ${ }^{23}$.

Cerca de quatro anos depois, a mesma entidade iria organizar a Segunda Semana Paulista de Medicina Legal, nessa edição toda dedicada à infortunística $^{24}$. A realização em si de tal certame é mais um testemunho da urgência que o tema demandava no meio. Nesse evento, Almeida Júnior, membro assíduo da Sociedade e das revistas especializadas, médico particularmente preocupado com questões relativas ao mundo do trabalho e da infância delinqüente, sintetizava a importância da atuação médica em infortunística:

«O que realmente interessa ao operário, ao patrão e à sociedade, é que não haja acidentes, e, para nos aproximarmos cada vez mais desse ideal, torna-se indispensável a cooperação ativa dos médicos. Cooperação no exame prévio do candidato a emprego, a fim de que se promova o tratamento antecipado dos doentes, o afastamento dos que representem perigo aos outros, e, ainda, a adaptação de cada operário ao tipo de atividade que mais lhe convenha. Cooperação, em seguida, na influência que a Medicina possa exercer sobre as condições de instalação, de organização e de regime de trabalho. Cooperação, finalmente, na educação preventiva do povo, e, particularmente, da classe operária» ${ }^{25}$.

A importância e prioridade conferidas a esse tema evidentemente respondiam às implicações econômicas que envolvia. Os infortúnios do trabalho eram, antes de tudo, fontes de prejuízos. Perdiam a indústria, as companhias seguradoras e os próprios trabalhadores. Em termos macroeconômicos, tudo acabava por se traduzir em perdas para o país. Além disso, e aqui aponta uma primeira identificação com o crime, o acidente de trabalho representava uma ruptura violenta do ordenamento harmônico que devia prevalecer no interior da fábrica, uma perturbação da ordem tão indesejável quanto os movimentos paradistas.

23 FÁvero, F. (1936), «Relatório do secretário geral», Arch. Soc. Med. Leg. Crim. S. Paulo, 7, (3), 149-153, p. 150.

24 Realizada de 4 a 9 de novembro de 1940. Organizada pela Sociedade de Medicina Legal e Criminologia de São Paulo e pela Sociedade de Medicina e Cirurgia de São Paulo. Flamínio Fávero, no discurso de encerramento, afirmava ter sido essa a primeira vez que o tema da infortunística merecia a realização de um evento como esse no país (FÁvERO, F. (1941), «Discurso de encerramento», Arq. Soc. Med. Leg. Crim. S. Paulo, 12, suplemento, 489-497, p. 490). Participaram advogados, engenheiros e médicos. 29 autores tiveram seus trabalhos publicados em anais.

25 AlMEIDA JÚNIOR (1941), p. 307. 


\section{A ANALOGIA CRIME-ACIDENTE, CRIMINOSO-TRABALHADOR}

Certamente também por originar-se das mesmas penas, mas não apenas por isso, o discurso voltado ao acidente de trabalho, o «ato anti-social» fabril, era estruturalmente análogo ao criminológico. Se o criminoso era portador de predisposições biológicas para o ato anti-social, potencializadas pelo ambiente, assim também o trabalhador com relação ao acidente. Da mesma forma como na criminologia o foco central de preocupação deveria estar no próprio criminoso, na medicina do trabalho a mesma ênfase se direcionava ao trabalhador. Crime e acidente se tornavam apenas indícios, ainda que fundamentais, para o real conhecimento do indivíduo que os «comete». Era o mesmo olhar especializado que transformava tanto o criminoso como o trabalhador em objetos de conhecimento médico-científico. Portanto, uma medicina do trabalho deveria antes de tudo se ocupar do

«(...) estudo da personalidade do trabalhador, do seu perfil morfológico e psíquico, de seus caracteres individuais, hereditários, raciais, normais e patológicos, em face do meio e de seus múltiplos elementos, ora solicitando qualidades apuradas para o bem, ora engravecendo ou despertando taras jacentes como gênese de doenças ou acidentes do trabalho» ${ }^{26}$.

Por isso também aqui o papel do médico era central, devidamente armado com suas teses prevencionistas. Mais uma vez, era o exame médico o instrumento essencial, o único capaz de encontrar, medir e classificar as predisposições. E assim era porque se identificava no fator humano a principal causa do acidente, como se verá a seguir.

\section{AS CAUSAS DOS ACIDENTES}

Como o crime, o acidente de trabalho teria causas externas, ou ambientais, e internas, ou individuais. As primeiras eram reconhecidas e algumas vezes discriminadas. No entanto, eram as últimas apenas que mereciam a atenção da medicina legal, ou porque consideradas como as únicas legitimamente pertencentes à alçada da medicina, ou porque assumidas como as mais importantes, ainda que muito raramente se encontrasse necessidade de alguma forma

26 Matuck, A. (1944), «Estudos médico-legais do acidente do trabalho e da doença profissional», Arquivos da Polícia Civil de São Paulo, 7, 133-180, p. 133. 
de comprovação dessa tese ${ }^{27}$. Era o que deixava claro Edmur Aguiar Whitaker, em si mesmo uma expressão da identidade entre as preocupações voltadas ao crime e ao acidente, já que a um só tempo era o mais destacado médico da polícia paulista e de seu laboratório de antropologia criminal ${ }^{28}$, e também um dedicado estudioso do tema da infortunística e da seleção e orientação profissionais ${ }^{29}$. Em trabalho apresentado em 1938 na Sociedade de Medicina Legal, Whitaker afirmava que: «Os acidentes de trabalho têm, em grande parte, uma origem humana. Não deixando de considerar a importância de toda uma série de problemas na prevenção dos desastres, o primeiro lugar cabe ao fator humano». (Grifo meu) ${ }^{30}$.

O mais interessante é que Whitaker se mostrava ciente das chamadas causas ambientais, reconhecia com perspicácia algumas delas e seu papel, o que termina por enfatizar ainda mais a sua priorização do fator humano:

«Todo o mundo está de acordo em que a má organização das indústrias, o fraco interesse que se toma pelo trabalho (...), ou outras circunstâncias ainda do ambiente, tais como as más condições devidas ao pessoal, a exagerada distância entre a habitação e o lugar do trabalho, as horas de trabalho estafante, contribuem em medida maior ou menor para a freqüência dos acidentes. Porém a mais severa responsabilidade cabe ao fator subjetivo inerente ao fator humano e às suas inaptid$\tilde{o} e s\rangle^{31}$. (Grifo meu).

27 Umas das poucas exceções, ainda que com dados escassos, aparece em PEREIRA, M. (1941), «O biótipo nos infortúnios do trabalho», Arq. Soc. Med. Leg. Crim. S. Paulo, 12, suplemento, 264-270, p. 265 e 266; e em MANGE, R. (1941), «A redução dos infortúnios do trabalho pela orientação, seleção e formação profissional», Arq. Soc. Med. Leg. Crim. S. Paulo, 12 , suplemento, 410-416, p. 412.

28 Criado em 1934.

29 Algumas de suas publicações acerca do tema são: WhitAKER, E. de A. (1936), «A orientação e selecção profissionaes em São Paulo. Novos methodos», Revista de Neurologia e Psychiatria de São Paulo, 2, 65-74; WhITAKER, E. de A (1938a), «A prevenção dos accidentes de transito e a selecção medico-psychotechnica dos conductores de vehiculos rapidos», Idort, (77), 102-107; e WHITAKER, E. de A (1938), A organização da orientação e selecção profissionaes no Instituto 'D. Escolastica Rosa', de Santos, em cooperação com a Cia. Docas. In: Whitaker, E. A., Atas do $1^{\circ}$ Congresso Paulista de Psychologia, Neurologia, Psychiatria, Endocrinologia, Identificação, Medicina Legal e Criminologia, São Paulo, 9-40.

30 Whitaker, E. de A. (1938b). «Importância da selecção médico-psychotéchnica dos indivíduos para a prevenção dos accidentes do trabalho», Arch. Soc. Med. Leg. Crim. S. Paulo, 9, (1-3), 16-21, p. 16.

31 Ibidem, p. 17. 
Outros autores admitiam igualmente o papel das chamadas «causas ambientais», ou «externas». No entanto, estas nunca mereciam qualquer espaço de discussão mais aprofundada. Apareciam quase sempre de forma abstrata, nomeadas em bloco. Sua articulação com as «causas internas» na etiologia dos acidentes e doenças profissionais era reconhecida, mas na posição subordinada de fatores condicionantes ou desencadeantes. Manuel Pereira, outro destacado membro da Sociedade de Medicina Legal, afirmava que a propensão a acidentes ou doenças do trabalho estava em função da «(...) maior ou menor capacidade de reação ou defesa (...)», e esta oscilava na dependência de fatotes definidos

«(...) em face da idade, da energia despendida nas atividades do trabalho ou ainda em conseqüência das condições de sua vida social, provocando o despertar de um fator interno, constitucional, a causalidade interna, que, colaborando com o fator externo, profissional, revelam a diminuição orgânica, a inaptidão para o trabalho e, do desequilíbrio, se origina, desta sorte, o acidente-tipo, a doença profis-

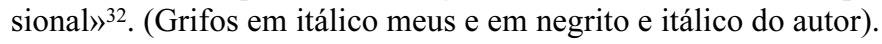

A tendência predominante entre os especialistas apontava, assim, para a culpabilização da vítima, o acidentado trazendo em si mesmo a causa do acidente. Mesmo um fator aparentemente resultante de elementos externos à constituição individual, expresso pelas «horas de trabalho estafante», a fadiga, podia ser biologizada e transformada em mais um elemento característico da predisposição a acidentes. $\mathrm{O}$ desgaste físico excessivo no trabalho fabril vêm desde os primórdios da industrialização, evidentemente. No Brasil dos anos 30, tampouco as relações de trabalho haviam avançado significativamente para domesticar as condições de exploração da mão-de-obra fabril e melhorá-las qualitativamente. Em alguns aspectos, a crise aberta com o colapso de 1929 inclusive ocasionou degradação do nível de vida, como demonstra Zélia Lopes da Sil$\mathrm{va}^{33}$. Particularmente, o aprofundamento da especulação imobiliária implicou no deslocamento das residências operárias para bairros distantes, longe das fábricas, o que indicava «(...) um agravamento das condições de sobrevivência da família operária, à medida que aumentam os gastos com transportes e também o desgaste físico de sua força de trabalho» ${ }^{34}$.

32 Pereira (1941), p. 265.

33 Silva, Z. L. da (1990), A domesticação dos trabalhadores nos anos 30, São Paulo, Marco Zero, p. 38 a 43.

34 Ibidem, p. 41. 
Mas o reconhecimento da fadiga operária não poderia se consolidar em consenso social. Além de, em si mesma, denunciar os níveis de exploração da mão-de-obra, a questão da fadiga poderia se transformar, nos primeiros anos 30, em uma variável importante do reordenamento das relações do mercado de trabalho que se processava a partir do Estado, particularmente na discussão das leis sobre férias e jornada de trabalho. Justamente para aumentar seu poder de barganha nesse debate, entidades representativas da burguesia industrial simplesmente negavam a existência da fadiga entre os operários:

«(...) o empregado de escritório é um intelectual, trabalha com o cérebro; o operário é um trabalhador braçal, cujo cérebro não dispende energias. Ninguém ignora que as pessoas submetidas a intenso esforço cerebral esgotam-se dentro de certo prazo e que os indivíduos acostumados a trabalho manual, intenso e repetido, mas cujo cérebro está habitualmente em repouso, dificilmente conhecerão esse esgotamento. (...) $\mathrm{O}$ trabalhador brasileiro aplica sua atividade, em geral, durante um horário suave e nas nossas fábricas não existe ainda aquela disciplina férrea em que o operário é compelido a dar sempre o máximo possível de rendimento» ${ }^{35}$.

A perspectiva médico-legal sobre a fadiga do operário não se distanciava desse discurso patronal. Se não chegava ao extremo de simplesmente negá-la, não reconhecia nela os condicionantes sociais. Um índice da superexploração da mão-de-obra, e como tal causador de acidentes, era apresentado como uma debilidade do indivíduo. Nas discussões e estudos sobre o tema, esta era a visão predominante no meio médico-legal. Por exemplo, um dos que assim fazia a abordagem do assunto era Aldo Mário de Azevedo, um engenheiro militante na área, autor inclusive de um projeto de lei sobre o assunto, e o fazia para a platéia predominantemente de médicos de uma sessão da $1^{\mathrm{a}} \mathrm{Se}-$ mana Paulista de Medicina Legal ${ }^{36}$ :

«Como o grau de fatigalidade varia de indivíduo a indivíduo, é de presumir-se que, para iguais condições de trabalho, devem ser mais sujeitos a acidentes os trabalhadores mais cansáveis, portanto, os mais fracos fisiológica ou psicologicamen$t e\rangle^{37}$. (Grifos meus).

35 Centro dos industriais de FiaÇão e tecelagem de Algodão (1990), Relatório de Diretoria 1929/32, Rio de Janeiro, p. 100. APUD: SILVA (1990), p. 64.

36 No mesmo evento, Augusto Matuck fornecia as convenientes explicações fisiológicas da individualização da fadiga. (MATUCK, A. (1937), «Factores de accidentes do trabalho», Arch. Soc. Med. Leg. Crim. S. Paulo, 8, suplemento, 517-531, p. 518-519).

37 AzEVEDo, A. M. de (1937), «A collaboração do médico na prevenção de accidentes», Arch. Soc. Med. Leg. Crim. S. Paulo, 8, suplemento, 299-310, p. 303. 
Voltamos assim ao terreno da predisposição. Nas palavras de Whitaker:

«A causa da maioria dos acidentes devidos ao fator humano deve ser procurada em uma predisposição para tal, que alguns trabalhadores possuem. Trata-se de uma disposição biopsíquica, posta em evidência por numerosas pesquisas»» ${ }^{38}$. (Grifos meus).

Se a predisposição era a causa principal dos acidentes, a causa da predisposição estaria na hereditariedade. Whitaker participava do entusiasmo comum de seu tempo e de sua ciência pela hereditariedade ${ }^{39}$. No caso do trabalho, afirmava mesmo que o exercício e a aprendizagem pouco poderiam fazer para alterar habilidades e debilidades adquiridas geneticamente ${ }^{40}$.

O percurso discursivo seguido era simples, mas de longo alcance: começava por priorizar o fator humano na casuística dos acidentes e em seguida transformava esse fator humano em predisposição biopsíquica, determinada principalmente de forma hereditária. Ao final dessa operação retórica, o papel do médico resultava imprescindível no que concernia à prevenção do acidente de trabalho, evento transformado em expressão de inadequações individuais de cunho biológico ao trabalho executado. O exame médico prévio e sistemático dos trabalhadores ganhava, dessa forma, uma importância decisiva também para a prevenção de acidentes de trabalho ${ }^{41}$. Era o exame que deve detectar as predisposições e aptidões do indivíduo e assim permitir uma colocação profissional ou funcional mais adequada. Evitar-se-iam assim os acidentes e de passo seria otimizado o rendimento do trabalho. Essa reivindicação era compartilhada por muitos e freqüentemente formulada nos ambientes médico-legais ${ }^{42}$.

No entanto, o exame médico prévio apenas não bastava. Ainda que necessário e indispensável, não passaria de uma fotografia do estado do indivíduo. Este poderia mudar rapidamente, sob a ação de uma diversidade de fatores, tais como «elementos patológicos eventuais, de intoxicação de origem dieté-

38 WhitAKer (1938b), p. 17.

39 Para uma análise do fetiche da hereditariedade desde fins do século XIX e por todo o século XX, ver Gould, S. J. (1999)[1981], A falsa medida do homem, São Paulo, Martins Fontes.

40 WHITAKER (1938b), p. 17.

41 A II Semana de Medicina Legal, dedicada à infortunística e realizada de 4 a 9 de novembro de 1940, aprovou uma moção, apresentada por Manuel Pereira, defendendo a generalização do «exame biotipológico prévio e reiterado durante o trabalho». (SESSÃO DE ENCErramento (1941), Arq. Soc. Med. Leg. Crim. S. Paulo, 12, suplemento, 485-488, p. 486).

42 Ver, por exemplo, BomfiM, R. da C (1936), « Prevenção dos accidentes do trabalho», Arch. Soc. Med. Leg. Crim. S. Paulo, 7, (1), 6-8, p. 7; e MAtUCK, A. (1936), «Factores de accidentes do trabalho (2a parte)», Arch. Soc. Med. Leg. Crim. S. Paulo, 7, (3), 108-109. 
tica (o álcool em primeiro lugar) ou ainda motivos ocasionais que venham perturbar ou alterar as condições psíquicas do indivíduo». Por isso Whitaker acabava por defender o controle e a vigilância permanente sobre os trabalhadores, principalmente se exerciam uma profissão perigosa. A «suspeita de presença do fator de perigo» sempre surgiria quando houvesse «alteração de conduta (...) e anomalias no exercício do mistér» ${ }^{43}$ Matuck compartilhava da mesma reivindicação:

«Mas, também, examinemos o trabalhador antes, muitas vezes durante, e periodicamente sempre, enquanto exerce o seu mister. Vamos desvendar-lhe no organismo a incompatibilidade para o serviço a que se propõe, removendo-a ou desviando-a (...).» ${ }^{44}$

Whitaker concluía defendendo a seleção e orientação profissionais como as soluções definitivas para o problema dos acidentes do trabalho, já que por meio delas «se eliminarão as deficiências humanas, causas preponderantes dos acidentes ${ }^{45}$.

\section{MEDICINA E RACIONALIZAÇÃO CIENTÍFICA DO TRABALHO: A SELEÇÃO E A ORIENTAÇÃO PROFISSIONAIS}

A medicina legal se considerava habilitada para postular uma participação no movimento racionalizador do processo produtivo ${ }^{46}$, que por sua vez buscava apoiar-se nas possibilidades que a ciência cada vez mais disponibilizava. Tal movimento já vinha dos anos 20 , mas foi a partir da crise de 29 , e por conta da crise econômica por ela desencadeada, que ganhou força ${ }^{47}$. Nos anos 30 , portanto, o Brasil procurou integrar-se de maneira mais decisiva ao processo de racionalização científica do trabalho que se configurava em paradigma a partir dos países industrializados, em torno dos princípios do taylo-

43 WhitAKer (1938b), p. 18.

44 MatucK, A. (1943), "Sugestões para a reforma da lei sobre acidentes do trabalho», Arq. Soc. Med. Leg. Crim. S. Paulo, 14, (1-3), 59-62, p. 60.

45 WhitAKer (1938b), p. 18.

46 Maria Clementina Pereira Cunha reflete sobre o papel da psiquiatria higiênica, à época tampouco plenamente diferenciada da medicina legal, na racionalização do trabalho (CUNHA, M.C. P. (1986), O Espelho do Mundo. Juquery - a história de um asilo, $2^{\mathrm{a}} \mathrm{ed}$., Rio de Janeiro, Paz e Terra, p. 186 a 192).

47 Silva (1990), p. 26. 
rismo-fordismo ${ }^{48}$. Sua estratégia central se definia pelo aprofundamento da separação entre o planejamento e a execução do trabalho, expropriando assim o trabalhador de seu saber-fazer ${ }^{49}$. Uma das conseqüências desse processo era a fragmentação do trabalho, apontando para especializações cada vez maiores:

«(...) essa diferenciação faz parte das transformações ocorridas com a implantação do sistema de fábrica, que, para se tornar vitorioso, precisou parcelar o processo de trabalho, possibilitando assim a fragmentação do trabalhador através de um sistema hierarquizado de 'funções' (...)» $\rangle^{50}$.

Resultava então que a distribuição da mão-de-obra nessas diversas funções passava a ser também um problema da racionalização do trabalho. A produtividade se tornava uma variável dependente da forma como a energia humana era distribuída pelo processo produtivo. Energias mal alocadas, contradizendo a natureza de cada trabalhador, suas tendências e predisposições, não apenas seriam fontes potenciais de acidentes, como desperdício material e perda de produtividade. Em qualquer caso, prejuízo ao empregador e, em última análise, à economia do país. Era aqui que o conhecimento médico reivindicava seu papel, oferecendo sua capacidade de conhecer os corpos e as predisposições, e postulava a prerrogativa de orientar a distribuição da energia humana pelo processo produtivo.

Mas também num outro sentido a contribuição da medicina poderia se fazer necessária. No caso brasileiro, a racionalização do trabalho significava mais do que disciplinarização da mão-de-obra. Tratava-se de sua adaptação ao mundo da fábrica, num momento em que o processo migratório desde as regiões mais pobres do país em direção às grandes cidades, São Paulo em particular, crescia muito, em substituição às igualmente crescentes restrições

48 Frederick W. Taylor e Henry Ford foram os responsáveis pelos dois modelos exemplares da racionalização industrial. O primeiro desenvolveu a teoria do gerenciamento científico, pela qual o processo de produção deveria ser subdividido em seus componentes mais básicos, e cada tarefa medida e cronometrada para maximizar a eficiência e a produtividade. Ford aperfeiçoou o taylorismo ao introduzir o sistema da esteira transportadora e a padronização industrial. Em países periféricos da economia capitalista, como o Brasil, a racionalização científica do trabalho, embasada nesses sistemas, era considerada uma estratégia prioritária para a modernização de suas economias. Para uma análise da circulação e da institucionalização dessas idéias no Brasil dos anos 30, com ênfase no que se dava em São Paulo, ver AnTONACCI, M. A. (1993). A vitória da razão - o IDORT e a sociedade paulista, São Paulo, Marco Zero.

49 Ibidem, p. 21.

50 Ibidem. 
à imigração por parte do governo Vargas. $\mathrm{O}$ adestramento do corpo às exigências do trabalho fabril implicava numa série de adaptações: à disciplina do uso fragmentado e regulado do tempo, aos horários de trabalho, aos ritmos de produção da fábrica e de cada máquina, passando pelo acondicionamento aos movimentos e manobras exigidas. O sucesso de tantas adaptações era a condição científica da prevenção de acidentes e do aumento da produtividade. E como o objeto central dessas tecnologias era o próprio corpo humano, resultava que cabia à medicina produzí-las e operacionalizá-las.

Imbuídos desses princípios e convicções, a comunidade médica envolvida com o tema buscava defendê-los e difundi-los socialmente. Sua referência teórica principal era Nicolas Pende, professor e médico italiano e um dos principais nomes da Escola Positiva em todo o mundo. Pende, em seu texto «Trabalhos recentes sôbre Endocrinologia e Psicologia Criminal», citava dados da «New Psychological Association» para exemplificar o aumento de riqueza de um país que seria possibilitado se «todo o cidadão de ambos os sexos fosse bem conhecido e utilizado socialmente segundo suas próprias aptidões». Para os Estados Unidos, esse valor seria de 70 milhões de dólares ao ano ${ }^{51}$. Pende explicava porque a biotipologia seria capaz de produzir esse milagre econômico:

«Somente homens exatamente conhecidos em sua qualidade biotipológica e racionalmente orientados para o ofício ou o trabalho mais conforme ao seu biótipo poderão fazer uma obra fecunda e dotar de máximo rendimento produtivo a técnica da moderna organização científica do trabalho; somente os homens que sejam plenos conhecedores de suas debilidades orgânicas e curados e corrigidos em tempo oportuno das mesmas poderão evitar facilmente os assaltos dos agentes infecciosos, dos agentes tóxicos, dos agentes traumáticos, dos fatores morbosos meteorológicos a que os expõe o trabalho (...).» ${ }^{52}$

E como mais uma vez se tratava de predisposições e tendências, a medicina se apresentava como a mais indicada para a tarefa. Na verdade, a metodologia científica que se propunha a identificar as predisposições ao acidente era a mesma que poderia determinar as aptidões profissionais. Manuel Pereira, em texto já citado, assim formulava a questão:

«(...) o estudo biotipológico autoriza-nos a 'colocar cada operário no lugar que merece; favorece-nos a obra de profilaxia contra as enfermidades e a prevenção contra os

51 Ássaly (1945), p. 42.

52 PENDE, N. Trabalhos recentes sôbre Endocrinologia e Psicologia Criminal, p. 129. Apud: ÁsSALY (1945), p. 42 e 43. 
acidentes; resolve de uma forma mais racional as questões médico-legais ligadas ao trabalho; constitui a base fundamental da proteção higiênica do operário'. Seria obra incompleta, se na preparação do ambiente das fábricas, oficinas, usinas, não se fizesse um estudo completo do elemento humano que aí trabalha (...).. ${ }^{53}$

O mesmo autor apontava as variáveis que deviam caracterizar cada tipo de trabalho: velocidade, habilidade, resistência e força. A partir da classificação de Nicolas Pende, os tipos constitucionais correspondentes a cada uma dessas qualidades seriam: biótipo longilíneo-tônico, biótipo longilíneo-flácido, biótipo brevilíneo estênico-tônico e o brevilíneo-flácido ${ }^{54}$.

Vale a pena seguir Manuel Pereira um pouco mais e ver como, a partir desse esquema metodológico e do tipo físico de cada um, ele disponibilizava ferramentas para desenhar uma nova sociedade, com suas forças humanas cientificamente distribuídas pelos conhecimentos da medicina:

«Com a aplicação, portanto, dos modernos preceitos da constituição individual, a Medicina do Trabalho pode prevenir, orientar e selecionar os operários para a espécie de trabalho adequado a cada tipo constitucional. Deste modo, por conseguinte, o longilíneo, possuindo força e rapidez muscular suficientes, habilidade motora e decisão rápida, está apto para as profissões mecânicas, metalúrgicas, de eletricidade, motorista. O biótipo longilíneo astênico, ao invés, deve ter ocupações nas quais não haja necessidade de força e resistência prolongada, apenas rapidez e mobilidade motora, para os ofícios leves e de precisão, como relojoeiro, tipógrafos, datilógrafos. Para o biótipo brevilíneo estênico, com força muscular, resistência neuro-muscular e neuro-psíquica e com relativa lentidão de movimentos e de decisão, deve ele ser encaminhado para os serviços de carpintaria, marcenaria, carreiro, lenhador, açougue. Por fim, o brevilíneo astênico, lento, de pouca resistência e força muscular, deve ser dirigido para os ofícios de cinzelador, ocupações de escritório, e ao desenho. Devem ainda evitar os trabalhos em que permaneçam muito tempo de pé, pela predisposição às varizes ou aos trabalhos sedentários, que dão lugar à obesidade, às dispepsias, às litíases ${ }^{55}$.

Essa espécie de utopia racionalizadora não era incomum no meio médicolegal ${ }^{56}$. No mesmo evento em que Manuel Pereira apresentava aos colegas tal

53 Pereira (1941), p. 265.

54 Ibidem, p. 268.

55 Ibidem, p. 268 e 269.

56 Whitaker propôs, na sessão de 30 de outubro de 1935 da Sociedade de Medicina Legal, que as escolhas das carreiras universitárias também obedecessem a «aconselhamentos» médico-científicos (WHITAKER, E. de A. (1935), «A selecção à entrada das Universidades», Arch. Soc. Med. Leg. Crim. S. Paulo, 6, (1), 104-106). 
perspectiva, em outra sessão Roberto Mange, engenheiro militante da causa da racionalização do trabalho, tratava da mesma questão:

«Assim, no volante de um automóvel teremos um motorista de boa capacidade de atenção dispersa e de reação rápida e segura, ao passo que no controle de um processo químico delicado e perigoso encontraremos um operador cuja memória pronta e precisa lhe indicará a qualquer instante, de acordo com as instruções recebidas, qual o modo de intervir. Em qualquer desses casos teremos assegurado o menor risco possível na execução da atividade profissional, não só para o operador como para a coletividade» ${ }^{57}$.

Alfredo Issa Ássaly, por sua vez, externava o seu entusiasmo pela biotipologia numa divisa que parecia sintetizar o modelo de gerenciamento médico do trabalho: «Conhecer os homens, valorizá-los, melhorá-los, utilizá-los, para o máximo rendimento do indivíduo e da coletividade ${ }^{58}$.

É importante reconhecer nessas propostas médicas de racionalização do trabalho o seu viés autoritário, na medida em que propunham que a escolha do ofício de um indivíduo dependesse de variáveis medicamente determinadas, e não de eventuais preferências ou conveniências do próprio indivíduo ${ }^{59}$. Isso se coadunava com a atmosfera ideológica predominante na época, que desvalorizava as concepções liberais de direitos individuais e enfatizava reiteradamente a supremacia do «bem comum» sobre interesses particulares. Escolher seu próprio trabalho e, pior, optar voluntariamente por não trabalhar, eram atitudes que o Estado cada vez menos estava disposto a tolerar, apoiando-se na retórica coletivista de cunho autoritário ${ }^{60}$. Ássaly, em comunicação à Sociedade de Medicina Legal, se colocava como intérprete dessas idéias:

57 MANGe (1941), p. 415.

58 Ássaly, A. (1942), «Serviço de Pesquisas Técnicas», Arquivos da Polícia Civil de São Paulo, 4, 285-305, p. 291.

59 Esse autoritarismo poderia chegar ao ponto de propor estabelecer as primeiras definições profissionais desde muito cedo na vida do indivíduo, como o faz Edmur Whitaker em Congresso médico de 1938: «Ao sair da escola primária os indivíduos passariam por um processo seletivo, que os dividiria em dois grupos, indivíduos aptos para os estudos secundários e aptos para o aprendizado profissional (...)». (WHITAKER (1938), p.12). O paradigma poderia ser o exame de inteligência «11+», aplicado na Inglaterra desde os anos 20 até os anos 60 , que direcionava $20 \%$ das crianças para escolas secundárias, destinadas a um futuro curso superior, e 80\% para escolas técnicas. (Gould (1999)[1981], p. 310 e 311).

60 Para uma análise do «solidarismo» republicano de fins do século XIX na França, em mais de um aspecto bastante similar ao discurso coletivista autoritário de Vargas, ver HARRIS (1993)[1989], p. 116. 
«À luz da filosofia individualista do trabalho, cada um tem o direito de empregar a sua atividade no que bem entender, ou de não empregá-la em coisa alguma. Mas contra essa concepção (...) a consciência moderna se levanta: todo o indivíduo que ficar inativo, não sendo inválido e estando em idade de trabalhar, falta ao primeiro dever que lhe impõe a sua qualidade de membro da sociedade, e o Estado pode e deve intervir para obrigá-lo a cumprir o seu dever, adotando as medidas apropriados a esse fim ${ }^{61}$.

Nesse sentido, também aqui se manifestava um aprofundamento da expropriação do saber-fazer do trabalhador e da separação entre o planejamento e a execução do trabalho, referidas há pouco.

Ainda que não caiba neste espaço uma análise extensiva do tema para além do universo de São Paulo, não se deve esquecer que tais idéias utópicas de organização social a partir da biotipologia não expressavam uma idiossincrasia restrita ao ambiente médico-legal paulista. A densidade científica que possuíam ${ }^{62}$ se expressava no intenso intercâmbio internacional que seus adeptos empreendiam, sempre a partir da referência patriarcal de Nicolas Pende. Refletia isso a grande freqüência de autores brasileiros em revistas internacionais dedicadas ao tema e vice-versa. Como exemplo interessante, pode-se aludir à publicação de um artigo de Leonídio Ribeiro e Walter Berardinelli na revista argentina «Anales de Biotipología, Eugenesia y Medicina Social» ${ }^{63}$. Os autores eram médicos e professores no Rio de Janeiro. Leonídio Ribeiro foi o criador do primeiro laboratório de antropologia criminal do Brasil, no início doas anos 30. Em 1933, havia recebido o prêmio Lombroso por seu trabalho sobre delinqüentes negros no Rio de Janeiro. O artigo referido possui uma síntese da concepção totalitária das potencialidades sociais da biotipologia:

«El conocimiento de la constituición individual es la base indispensable para el ejercicio de todas las actividades humanas; en la escuela y en el campo de la edu-

61 Ássaly, A. (1943), «Quatro dias entre quatrocentos vagabundos», Arquivos da Polícia Civil de São Paulo, 5, 21-54, p. 23.

62 Como científico se considera aqui o que a própria sociedade da época assim considerava, conforme as concepções de Thomas Kuhn. Daí a inexistência das aspas ou do prefixo «pseudo» (KuHN, T. (1998)[1962]. A estrutura das revoluções científicas, 5. ed., São Paulo, Perspectiva).

63 Para conhecer um pensamento mais acabado de concepção de organização social a partir de critérios biológicos, e também como outro exemplo da circulação internacional dessas idéias, ver a proposta de biocracia que Edouard Toulouse à mesma época fazia à sociedade francesa em CAMPOS MARín (1998), R. La gestión de la desigualdad: la utopía biocrática de Edouard Toulouse. In: Huertas, R. e OrTiz, C. (eds.) (1998). Ciencia y fascismo, Madrid, Doce Calles. 
cación física, para el establecimiento de grupos homogéneos; en el escritorio y en la oficina, para la vinculación y la selección profesionales; en los tribunales y en las penitenciarías, para la individualización de la pena, reeducación y cuidado de los delincuentes; en la política, en la administración, en la sociedad, para que cada uno tenga, biológicamente, su lugar adecuado; en las organizaciones de sanidad pública, en los servicios de profilaxis; y, finalmente, en la Eugenia, sobre todo, en la campaña de profilaxis del crimen, tomando como base el conocimiento precoz de la 'constituición delicuencial' (...).»»

Esse corpo doutrinário é interessante enquanto objeto de reflexão histórica por si próprio. Independentemente de que tenha sido transformado em realidade concreta, ou da extensão em que possa tê-lo feito, o discurso médico biotipológico merece ser devidamente conhecido e estudado. Até mesmo porque o discurso produzido por uma comunidade científica é uma realidade em si mesma, testemunhando sua visão de mundo e suas preocupações prioritárias e estratégias mais valorizadas para seu reconhecimento social. No entanto, igualmente pertinente é conhecer alguns casos empíricos de aplicação dessas idéias. Quando a idéia procura ganhar concretude, deixa-se conhecer ainda melhor, e ajuda a iluminar a realidade mais ampla que a condiciona. Um exemplo interessante pode ser fornecido por um processo seletivo que a Light $^{65}$ promoveu em 1940, onde as teses médicas fortemente influenciadas pela biotipologia procuraram orientar os critérios de escolha dos candidatos.

\section{UM CASO EXEMPLAR DE SELEÇÃO PROFISSIONAL MEDICALIZADA: A LIGHT}

Augusto Matuck era o nome da Sociedade inevitavelmente associado à infortunística. A maioria de seus estudos apresentados nas sessões da entidade tratavam do tema, tornando-o uma referência obrigatória. Em 1940, Matuck era também médico do Hospital da Light. Esta condição lhe proporcionava um espaço privilegiado para a aplicação empírica de muitas de suas concepções relacionadas com a seleção e a orientação profissionais. Sobre os processos seletivos, Matuck defendia não apenas a generalização do exame prévio, mas também sua sofisticação e detalhamento. Por isso, criticava a insuficiência do exame clínico realizado quando da concessão da carteira de trabalho, inca-

64 Ribeiro, L. e Berardinelli, W. (1939), «Biotipologia criminal», Anales de Biotipología, Eugenesia y Medicina Social, (83), p. 15. Devo esta referência a Gustavo Vallejo.

65 A Light era uma companhia de capital multinacional com enorme peso na economia brasileira da época, principalmente no setor de energia elétrica e serviços públicos urbanos. 
paz de preencher as necessidades protagonizadas por um verdadeiro exame prévio, que pudesse «convencer [o empregador] de haver encontrado a quem entregar uma modalidade de trabalho.» Considerava o autor que os avanços nesse campo estariam perfeitamente compatibilizados com o movimento pela racionalização do trabalho que o IDORT ${ }^{66}$ inaugurava ${ }^{67}$. Por um lado, o exame prévio protegeria a indústria de «contratações infelizes», de trabalhadores com preexistências mórbidas ou inadaptações profissionais, evitando perda de produtividade, acidentes e doenças do trabalho, incluindo nestes caso indenizações «injustas» pelo desconhecimento de lesões pré-existentes, com repercussões ao final das contas econômicas. Por outro, se revestia de profundo «sentido humanitário de se poupar ao holocausto de certas indústrias os mal precatados, os ignorantes ou desconhecedores da invalidez iminente». Enfim, «adotando-o, o fornecedor do emprego defende o seu patrimônio industrial realizando uma bela campanha de sentimentos nobres preservando da morte e da invalidez um sem número de homens, mulheres e crianças» ${ }^{68}$.

É interessante, portanto, conhecer como seria o exame prévio preconizado por Matuck. Preferencialmente, não deveria ser realizado por um único médico, mas por «juntas julgadoras especializadas», evitando-se assim a vulnerabilidade de critérios excessivamente pessoais. $\mathrm{O}$ exame propriamente dito deveria produzir uma ficha que contivesse os

\begin{abstract}
«(...) antecedentes, familiares e pessoais, uma documentação biológica, roentgenograma torácico, rigoroso controle de análises de sangue, urina, escarro, etc; registro dos estados funcionais dos aparelhos respiratório, circulatório, nervoso, renal, visual, auditivo, ósteo-muscular, etc., moléstias infecto-contagiosas, venéreas, assim como heranças mórbidas» ${ }^{69}$.
\end{abstract}

Para Matuck, o exame prévio devia ser complementado pelo exame periódico e sistemático, a ser realizado a cada um ou dois anos, permitindo ao trabalhador o acompanhamento de sua própria saúde, e ao empregador a decisão sobre a «(...) conveniência de se manter, de se afastar ou de se deslocar apenas periódica ou definitivamente o trabalhador, a juízo médico» ${ }^{70}$.

66 Instituto de Organização Racional do Trabalho. Sobre o tema, consultar ANTONACCI (1993).

67 Matuck, A. (1941), «O exame médico prévio do operário», Arq. Soc. Med. Leg. Crim. S. Paulo, 12, suplemento, 280-298, p. 281 a 283.

68 Ibidem, p. 283.

69 Ibidem, p. 284.

70 Ibidem. 
Toda essa estrutura médico-laboral estava, segundo Matuck, modelarmente em vigência nas Novas Construções da Light, sob sua coordenação ${ }^{71}$. E como exemplo paradigmático, era apresentado um relatório com os dados de um processo seletivo na dita empresa, no qual 8068 candidatos foram submetidos a exames médicos. O relatório consta, na verdade, de uma listagem de ocorrências médicas que justificaram as recusas ocorridas, com o total verificado para cada uma delas ${ }^{72}$. Considerando-se que um mesmo candidato recusado poderia tê-lo sido por mais de uma razão médica, os dados não permitem conhecer o total de candidatos recusados, mas sim os motivos da recusa com os respectivos totais. A lista é bastante extensa, testemunhando também a complexidade do exame. Inclui, por exemplo, queimaduras, existência de cicatrizes, conjuntivites, estrabismos, laringites, deformidades da caixa toráxica, úlceras, varizes, gripes, gagueiras, malária, sífilis, dentre muitas outras possíveis razões de exclusão. Não cabe aqui discutir as concepções de patologia e normalidade embutidas nessa lista, mas alguns ítens merecem alguma atenção. O próprio autor destacava um deles, afirmando que não podia

«(...) dar ingresso aos que se apresentaram em condições péssimas de robustez, acusando emagrecimento pronunciado. Os longilíneos nessas condições formaram a maioria, pois sabemos o quanto a desproporção entre o peso total do corpo e altura impressionam ao exame médico» ${ }^{73}$.

282 candidatos, $3,5 \%$ do total, foram recusados por apresentarem «desproporção entre peso e altura». Tal tipo de desproporção, nesse caso atuando como fator determinante do destino profissional de muitos candidatos, é todavia capaz de impressionar também ao historiador. É difícil não reconhecer aqui sobrevivências da primazia da morfologia no julgamento das qualidades humanas que tanto sucesso teve nos tempos de Cesar Lombroso. Desproporções físicas denunciavam a desarmonia corporal, que por sua vez denunciava desarmonias espirituais, de ordem moral e intelectual.

Outra causa médica de recusa que consta do relatório e pede alguma reflexão são as cicatrizes. Elas ali aparecem ou simplesmente não adjetivadas ou adjetivadas de muitas formas diferentes: «cicatrizes das faces frontais»,

71 Um outro artigo, de outro médico da Light, informa que, além do exame prévio, também o periódico era executado na Companhia, com reflexos positivos na prevenção de acidentes. (BRAGANÇA, U. (1941), «Estatísticas comparativas de acidentes do trabalho nas construções hidro-elétricas», Arq. Soc. Med. Leg. Crim. S. Paulo, 12, suplemento, 458-484, p. 483).

72 Os dados foram também discriminados por nacionalidade dos candidatos.

73 MATUCK (1941), p. 285. 
«cicatrizes por ferimentos antigos», «cicatrizes nos membros inferiores», «cicatrizes de operação de hérnia», "cicatrizes na parede abdominal», "cicatrizes por queimaduras», etc. Inevitavelmente, se conclui que possuir algum tipo de cicatriz, independentemente da causa, implicava em rejeição. A cicatriz parece então se constituir em um estigma em si mesma, um estigma que denuncia alguma debilidade: orgânica, no caso de resultante de alguma cirurgia; moral, no caso de ser causada por ferimento de luta; ou ainda orgânica, mas num outro sentido, quando os ferimentos, incluindo as queimaduras, denunciavam uma predisposição a acidentes. Enfim, não parecia prudente contratar trabalhadores portadores de cicatrizes, por conta justamente da possibilidade da existência de ao menos alguma dessas debilidades. Um total de 209 cicatrizes está registrado como causa de rejeição no relatório ${ }^{74}$.

Por fim, deve ser discutido o caso da reprovação de um candidato por possuir «epilepsia em família» ${ }^{75}$. Caso solitário, mas emblemático, por confluir no exame de um indivíduo tanto a forte influência da crença no determinismo hereditário, como a igualmente forte estigmatização do epiléptico. $\mathrm{O}$ epiléptico era associado cientificamente com comportamentos anômalos e anti-sociais ao menos desde Lombroso ${ }^{76}$. E como o estigma da epilepsia se transferia com o sangue familiar, a reprovação do candidato resultava assim justificada ${ }^{77}$.

O fundamental desse processo seletivo para nossa análise é a densidade de poder que a medicina de orientação biotipológica acabou por incorporar quando teve oportunidade para tal. Ainda que não tenha se generalizado, um caso concreto de seleção profissional dirigida nesses moldes foi apresentado à comunidade científica como paradigma bem sucedido. Em plena década da depressão econômica e do desemprego massivo, milhares de homens fizeram fila às portas da Light em busca de um trabalho e de uma vida melhor, levando consigo para a devida apreciação e julgamento nada mais que seu próprio corpo.

74 Erving Goffman, em seu trabalho sobre os estigmas, alude à cicatriz enquanto desvantagem cuja «importância na adaptação social e emocional abarca inconscientemente tudo». (GofFMAN, E. (1970)[1963], Estigma - la identidad deteriorada, Amorrortu, Buenos Aires, p. 21).

75 MATUCK (1941), p. 289.

76 Ver Lombroso, C. (2001) [1876], O homem delinqüente, Porto Alegre, Ricardo Lenz, p. $25,232,262,331$ e 333.

77 Goffman chama a atenção também para os mecanismos de transmissão do estigma aos que convivem com o estigmatizado (GoFFMAN (1970)[1963], p. 63). 


\section{CONCLUSÃO}

A medicina legal dos anos 30 se caracterizava pela amplitude de sua atuação. E por todos os ambientes por onde se movimentava, acabava por tratar do tema do trabalho. Seja na prisão ou na fábrica, na fila do emprego ou na «casa de correção», o trabalho era considerado uma estratégia disciplinar e médica a um só tempo, imprescindível na busca da estabilização social. O que se manipulava de fato era um binômio constituído pelo trabalho e pelo corpo humano. A tarefa do médico consistia em harmonizar os pólos deste binômio da melhor maneira possível. Nas instituições penitenciárias, tratava-se de encontrar o trabalho que atendesse às necessidades terapêuticas do condenado, e para isso se fazia necessário o conhecimento detalhado do próprio condenado, suas deficiências de personalidade e suas predisposições mórbidas. Na fábrica e no mercado de trabalho em geral, pouca coisa diferia na essência metodológica dessa tarefa, já que o objetivo ali seria conhecer e adaptar as tendências do indivíduo a um ofício determinado, para melhorar a produtividade e também evitar acidentes e doenças profissionais. Em todos os casos, a medicina se apresentava com todo um otimismo científico portador de grandes promessas.

Como se pretende tenha ficado claro ao longo destas páginas, este artigo ainda está a falar de medicina, poder e controle social, na esteira dos estudos de Michel Foucault e de autores como Roberto Machado ${ }^{78}$, no Brasil. Ainda que os anos setenta, época em que estes autores mais produziram e fizeram escola, estejam a cada dia mais distantes, a reflexão que provocaram ainda possui muitas pertinências. Evidentemente, o debate imprimiu ao longo desses anos muitas relativizações àquelas teses ${ }^{79}$, e este artigo procurou modestamente não negligenciá-las. Ainda que não tivesse sido o caso aqui de uma abordagem, ainda que tangencial, dessa importante discussão, e desde logo não era esta a intenção, não houve por onde ignorar que o material pesquisado indicava insistentemente a sujeição de destinos humanos de significativas parcelas da população a projetos e perspectivas médicas. $\mathrm{O}$ trabalho enquanto objeto de uma medicina legal impregnada de determinismos biológicos havia se transformado em estratégia de gerenciamento de seres humanos, seja como terapêutica penal, seja como força produtiva. $\mathrm{O}$ discurso que tratava do tema o fazia em perfeita articulação e complementariedade com outros discursos então bastante difundidos: o da Escola Positiva de criminologia e o de «valo-

78 Ver MACHADO (1978).

79 Como bem demonstra, para o caso brasileiro, Flávio Edler em EDLER, F. C (1998), «A medicina brasileira no século XIX: um balanço historiográfico», Asclepio, 50, 169-186. 
rização» e racionalização científica do trabalho. Daí sua história de relativo sucesso na época e suas implicações práticas, ainda que parciais, em fábricas, penitenciárias e casas de correção. Evidentemente, esse projeto de gerenciamento do trabalho por critérios médicos biotipológicos não atingiu a concretude e disseminação com que sonhavam seus adeptos, mas sem nenhuma dúvida teve impacto no debate científico e na própria realidade. Poderiam dizêlo os desempregados de então que perambulavam espreitados pelas ruas da cidade, talvez com maior autoridade aqueles portadores de incômodas «desproporções entre peso e altura»... 